\title{
Transmembrane transport of copper(I) by imidazole-functionalised calix[4]arenes
}

Nathan Renier, ${ }^{\mathrm{a}}$ Olivia Reinaud, ${ }^{\mathrm{b}}$ Ivan Jabin, ${ }^{* \mathrm{c}}$ and Hennie Valkenier*a

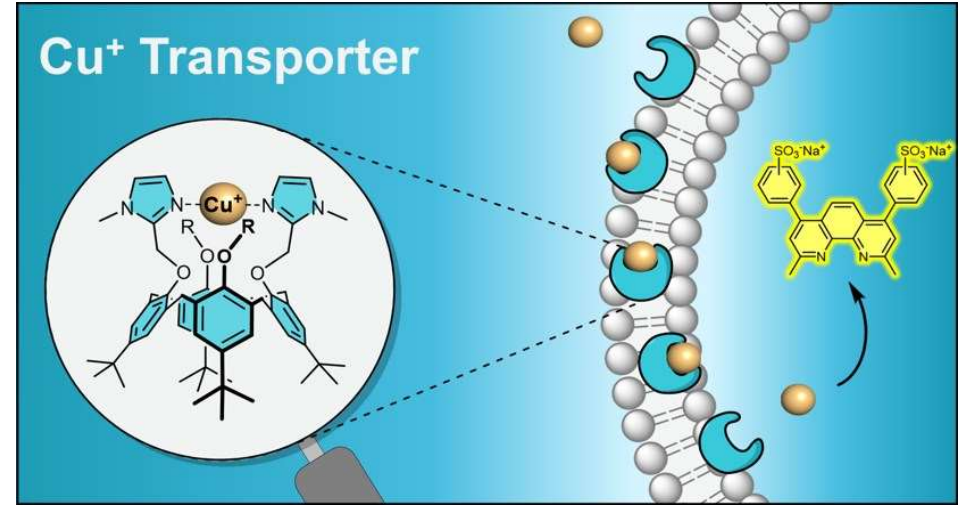

Here we present the first synthetic transmembrane transporters for $\mathrm{Cu}^{+}$. Calix[4]arenes with two imidazole groups have a linear coordination motif, which allows selective $\mathrm{Cu}^{+}$extraction into chloroform. Transmembrane transport of $\mathrm{Cu}^{+}$into liposomes was investigated with a newly developed assay and the results open the way to biomedical applications of these $\mathrm{Cu}^{+}$ionophores.

Copper ions are involved in fundamental metabolic processes in living organisms, such as cellular respiration, and numerous enzymes use copper in their active site, taking advantage of its redox and catalytic properties. ${ }^{1}$ Therefore, the intake of copper and its transport across cellular and organellar membranes are essential. Membrane proteins transport copper across lipid bilayers as $\mathrm{Cu}^{+}{ }^{2}$ Dysfunctioning $\mathrm{Cu}^{+}$transport due to mutations in the genes encoding for such proteins leads to disruption of copper homeostasis and causes serious health problems. Examples are Menkes disease, characterised by neurological and muscular defects caused by copper deficiency, and Wilson's disease, characterised by the accumulation of copper in the liver due to inefficient secretion. ${ }^{3}$

A potential way to restore $\mathrm{Cu}^{+}$homeostasis could be by facilitating $\mathrm{Cu}^{+}$transmembrane transport with synthetic molecules acting as cationophores. 4,5 Transport of cations by small molecules has already been observed with naturally occurring cationophores, such as monensin and valinomycin. These cationophores bind cations, extracting them from the aqueous phase into the lipid bilayer, to then carry them across

\footnotetext{
aniversité libre de Bruxelles (ULB), Ecole polytechnique de Bruxelles, Engineering Molecular NanoSystems, Avenue Franklin Roosevelt 50, 1050 Brussels, Belgium. Email: hennie.valkenier@ulb.ac.be

b. Université de Paris Descartes, Laboratoire de Chimie et Biochimie

Pharmacologiques et Toxicologiques, 45 rue des Saints-Pères, Paris, France.

Université libre de Bruxelles (ULB), Faculty of science, Laboratoire de Chimie Organique, Avenue Franklin Roosevelt 50, 1050 Brussels, Belgium.

Email:ijabin@ulb.ac.be

+ Electronic Supplementary Information (ESI) available: Experimental data, NMR
} spectra, BCS transport assays. See DOI: 10.1039/x0xx00000x the membrane. Monensin is able to collapse $\mathrm{Na}^{+}$and $\mathrm{H}^{+}$ gradients, leading to antibacterial effects and thus applications as antibiotic. ${ }^{6}$ Similarly, valinomycin is able to complex and transport $\mathrm{K}^{+}$and also has antibacterial properties. ${ }^{4}$

These transport properties are not limited to naturally occurring molecules, small synthetic molecules have been shown to transport cations, such as $\mathrm{K}^{+}, \mathrm{Na}^{+}, \mathrm{Ag}^{+}, 7$ and also $\mathrm{Zn}^{2+}$ and $\mathrm{Cu}^{2+} .{ }^{8-}$ 10 While ionophores for many different cations have been described, ionophores able to transport $\mathrm{Cu}^{+}$across lipid bilayers have, to the best of our knowledge, not been reported. ${ }^{11}$

Reinaud and co-workers developed calixarene 1, which is functionalised with two imidazole groups on its narrow rim, to act as an efficient $\mathrm{Cu}^{+}$receptor in organic solvents (Figure 1a). ${ }^{12}$ The $\mathrm{X}$-ray crystal structure showed that the imidazole nitrogen atoms bind to $\mathrm{Cu}^{+}$in a linear geometry $(\mathrm{N}-\mathrm{Cu}-\mathrm{N}),{ }^{12}$ analogous to the structure observed in proteins that have two histidines coordinating to $\mathrm{Cu}^{+} .{ }^{13-15} \mathrm{~A}$ water soluble version of $\mathbf{1}$, was shown to selectively complex $\mathrm{Cu}^{+}$in water in the presence of competing $\mathrm{Na}^{+}, \mathrm{K}^{+}, \mathrm{Mg}^{2+}, \mathrm{Ca}^{2+}, \mathrm{Zn}^{2+}$ and $\mathrm{Cu}^{2+}$ ions. ${ }^{16}$ Here we describe a series of calix[4]arenes with two imidazole groups and their ability to bind $\mathrm{Cu}^{+}$and transport this cation across membranes. a)

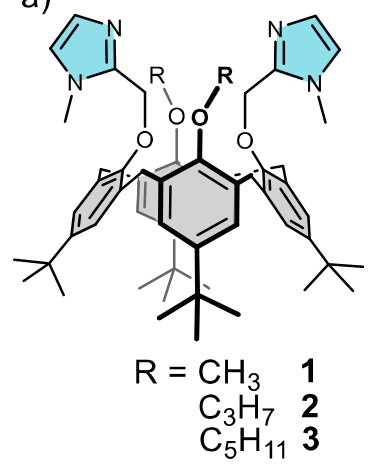

b)

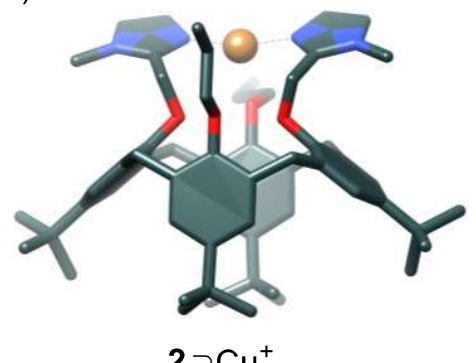

$2 \supset \mathrm{Cu}^{+}$
Fig. 1 a) Structure of the $\mathrm{Cu}^{+}$ionophores 1,2 and 3. b) Molecular model of complex $2 \supset \mathrm{Cu}^{+}$ with $\mathrm{Cu}^{+}$bound by the imidazole groups. ${ }^{17}$ 
The binding abilities of ligand $\mathbf{1}$ and its sufficient lipophilicity (clogP 15) ${ }^{18}$ make it a good candidate for the transmembrane transport of $\mathrm{Cu}^{+}$. However, the methoxy-through-the-annulus rotation of the anisole units of $\mathbf{1}$ confers a high flexibility to this ligand. We thus synthesised the more rigid propyl and pentyl analogues 2 and 3 (clogP 17 and 19, Figure 1a). While the ${ }^{1} \mathrm{H}$ NMR signals of the free receptor 1 in $\mathrm{CDCl}_{3}$ were very broad, the signals of $\mathbf{2}$ and $\mathbf{3}$ are much sharper (see ESI), which is a consequence of locking of the macrocycle into a cone conformation, as any group larger than ethyl prevent the transannular rotation of the phenyl units. ${ }^{19}$ The molecular model of complex $2 \supset \mathrm{Cu}^{+}$(Figure $1 \mathrm{~b}$ ) suggested that the binding of $\mathrm{Cu}^{+}$by the imidazole units was not affected by the replacement of methoxy by propoxy groups, as this model of $2 \supset \mathrm{Cu}^{+}$strongly resembles the X-ray crystal structure of $1 \supset \mathrm{Cu}^{+}$.

The ability of calixarenes 1-3 to bind $\mathrm{Cu}^{+}, \mathrm{Na}^{+}$, and $\mathrm{K}^{+}$in organic solvents was evaluated by ${ }^{1} \mathrm{H}$ NMR spectroscopy in a 4:1 mixture of $\mathrm{CD}_{3} \mathrm{CN} / \mathrm{CDCl}_{3}$. The quantitative formation of their complexes with $\mathrm{Cu}^{+}$and $\mathrm{Na}^{+}$was observed upon addition of only 1 eq. of cation indicating an affinity higher than $10^{5} \mathrm{M}^{-1}$ (Figures S14-S16). The low affinity of $\mathbf{2}$ for $\mathrm{K}^{+}$allowed the determination of a Log $K_{\mathrm{a}}=3.3$ (Figure S17-18). Through competition studies, the Log $K_{\mathrm{a}}$ values of $\mathbf{2}$ for $\mathrm{Na}^{+}$and $\mathrm{Cu}^{+}$were estimated to be 7.5 and 7.0 (Figure S19).

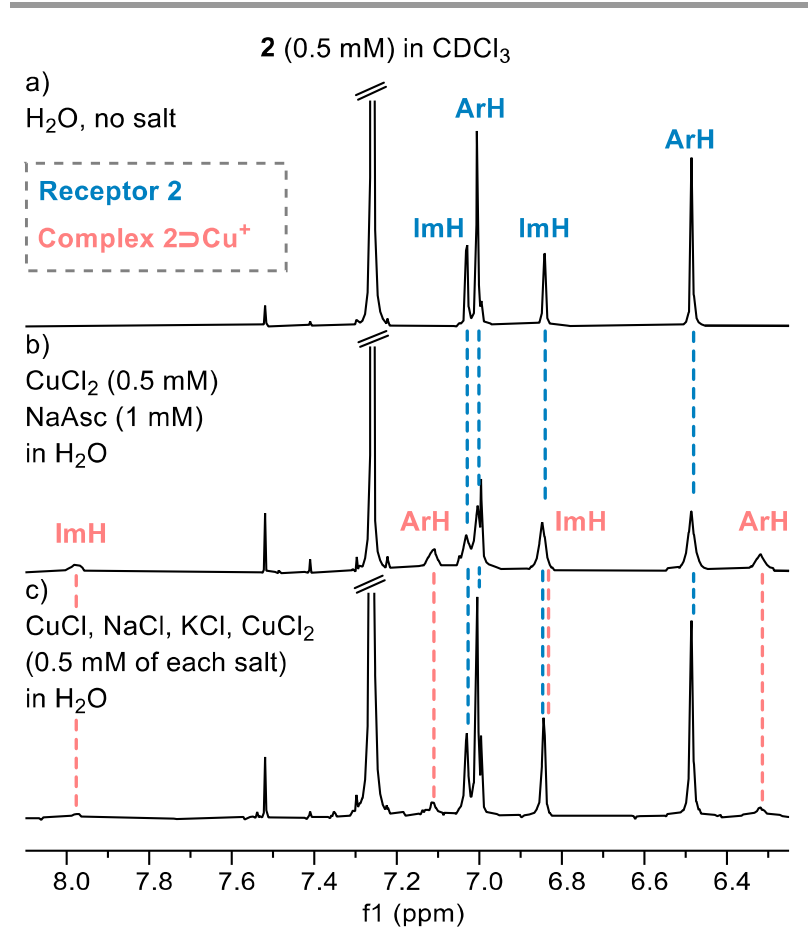

Fig. 2 Results from the extraction studies. Partial ${ }^{1} \mathrm{H}$ NMR spectra $(298 \mathrm{~K}, 400 \mathrm{MHz})$ of 2 in $\mathrm{CDCl}_{3}$ after addition of a) $\mathrm{H}_{2} \mathrm{O}$; b) $\mathrm{CuCl}_{2}$ with sodium ascorbate in $\left.\mathrm{H}_{2} \mathrm{O} ; \mathrm{c}\right) \mathrm{NaCl}, \mathrm{KCl}$, $\mathrm{CuCl}$, and $\mathrm{CuCl}_{2}$ in $\mathrm{H}_{2} \mathrm{O}$. "ImH" refers to the imidazole groups and "ArH" to the phenyl groups.

The binding of cations by calixarene $\mathbf{2}$ was further investigated with extraction studies from aqueous solutions into chloroform (Figure 2), as a model for the first step of transmembrane transport by cationophores. Multiple aqueous salt and acid solutions $\left(\mathrm{NaCl}, \mathrm{KCl}, \mathrm{CuCl}, \mathrm{HCl}, \mathrm{CuCl}_{2}\right.$, and $\mathrm{CuCl}_{2}$ with sodium ascorbate to generate $\mathrm{Cu}^{+}$in situ) were mixed with 2 in $\mathrm{CDCl}_{3}$ and the resulting samples were analysed by ${ }^{1} \mathrm{H} \mathrm{NMR}$ spectroscopy (Figure S20). The ${ }^{1} \mathrm{H}$ NMR spectra showed a new set of signals only for the samples where $\mathrm{Cu}^{+}$was present (Figure $2 \mathrm{~b}$ vs 2a). The appearance of the same signals was observed when multiple salts were added simultaneously (Figure 2c). These new signals were unambiguously assigned to the $\mathbf{2} \supset \mathrm{Cu}^{+}$complex (Figure S21). This showed that $\mathbf{2}$ is able to selectively extract $\mathrm{Cu}^{+}$from an aqueous phase into chloroform and that the selectivity observed with the water soluble version of 1 in an aqueous environment ${ }^{16}$ is retained in a biphasic system.

The ability of calixarenes 1-3 to transport $\mathrm{Cu}^{+}$was studied by fluorescence spectroscopy in a newly developed assay, using bathocuproine disulphonate (BCS). BCS is a fluorescent water soluble phenantroline derivative that can be used as a fluorescent dye for the sensing of $\mathrm{Cu}^{+}$through the formation of a non-fluorescent 2:1 complex (Figure 3a). ${ }^{20}$ Calixarenes 1-3 were pre-incorporated into the membrane of POPC/cholesterol (7:3) large unilamellar vesicles (LUVs, diameter $\sim 0.2 \mu \mathrm{m}$ ) at 1:500 receptor:lipids ratio (Figure $3 \mathrm{~b}$ ). $0.5 \mathrm{mM}$ BCS was encapsulated and the liposomes were suspended in sodium phosphate buffer $(50 \mathrm{mM}, \mathrm{pH}$ 7). A Cu+ solution prepared from $\mathrm{CuCl}_{2}(0.5 \mathrm{mM})$ and sodium ascorbate $(1 \mathrm{mM})$ was added to the liposomes to create a $0.03 \mathrm{mM} \mathrm{Cu}^{+}$gradient, while the fluorescence intensity of BCS at $393 \mathrm{~nm}$ (excitation at $278 \mathrm{~nm}$ ) was monitored. After addition of the $\mathrm{Cu}^{+}$, a decrease of the fluorescence intensity was observed for the samples containing calixarenes 1-3, but not for the liposomes without receptor (Figure 3 a), which implies transport of $\mathrm{Cu}^{+}$into the liposomes.
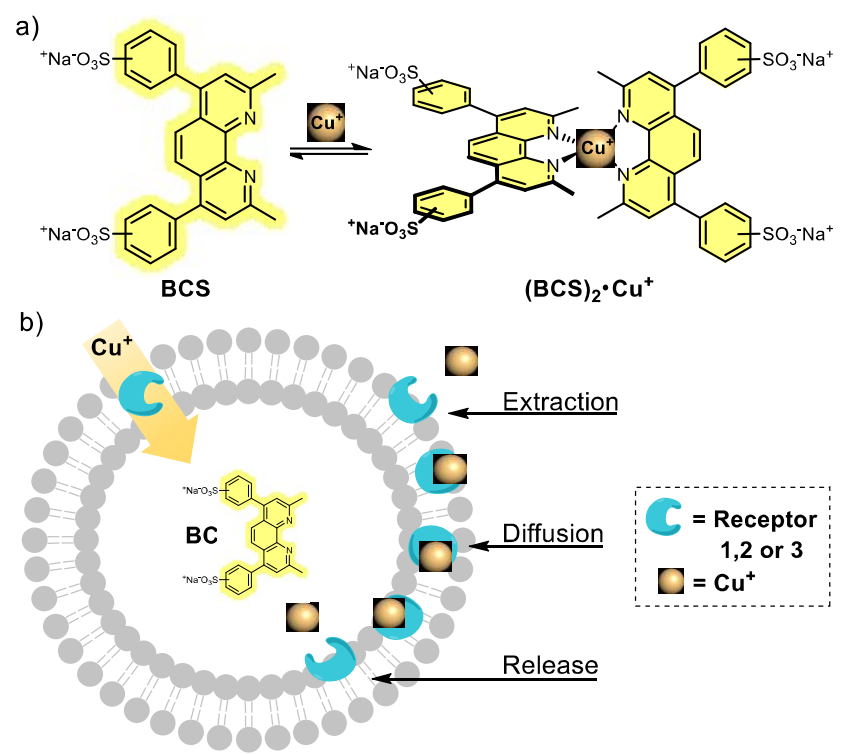

Fig. 3 a) Formation of the non-fluorescent 2:1 $\mathrm{BCS} \bullet \mathrm{Cu}^{+}$complex. ${ }^{20} \mathrm{~b}$ ) The transmembrane transport assay for $\mathrm{Cu}^{+}$into liposomes and proposed mechanism for the transport.

The decrease of fluorescence was faster for $\mathbf{2}$ and $\mathbf{3}$ than for $\mathbf{1}$, indicating that $\mathbf{2}$ and $\mathbf{3}$ transport $\mathrm{Cu}^{+}$at higher rates than $\mathbf{1}$. The transport rates were quantified by fitting the curves to single and double exponential decay functions to determine the halflives and the initial rates of transport (see ESI for details). The 
initial rate of $\mathrm{Cu}^{+}$transport was more than 2 times higher for 2 $\left(0.0015 \mathrm{~s}^{-1}\right)$ and $\mathbf{3}\left(0.0018 \mathrm{~s}^{-1}\right)$ than for $\mathbf{1}\left(0.006 \mathrm{~s}^{-1}\right)$ and the halflife was almost 2 times lower for $\mathbf{2}$ (70 s) and $\mathbf{3}$ (75 s) than for $\mathbf{1}$ (120 s) (Figure S25). These higher transport rates by 2 and 3 compared to $\mathbf{1}$ can be attributed to the locked cone conformation of those compounds, while the similarity in rates between $\mathbf{2}$ and $\mathbf{3}$ indicates that the increased lipophilicity has a negligible effect on the rates of transport by these calixarenes. A fragment of $\mathbf{2}$ with a single imidazole group (4) and a calix[4] arene without imidazole groups $(5)^{21}$ (Chart 1 ) did not show any transport (Figure 4a), showing that coordinating imidazole groups and their preorganisation on the calix[4]arene-based platform are necessary for $\mathrm{Cu}^{+}$transport activity.

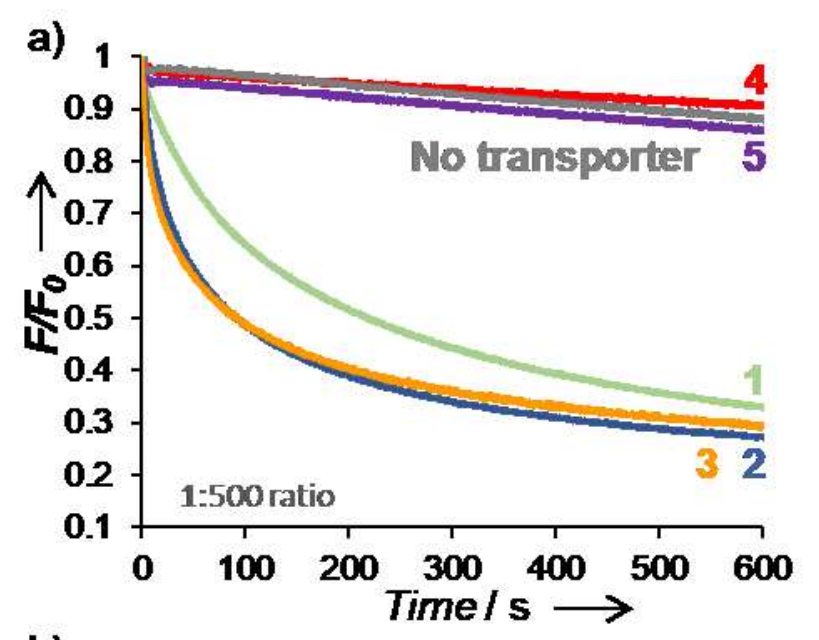

b)

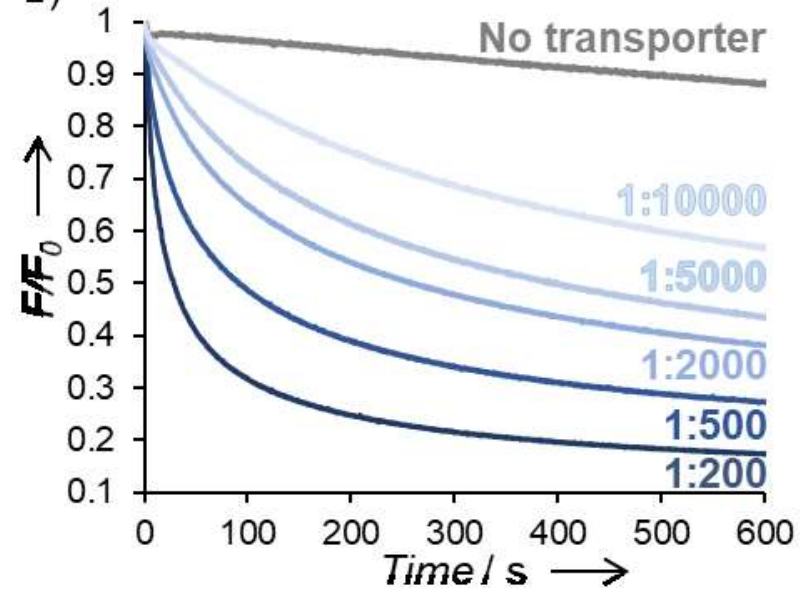

Fig. 4 Transport measurements of $\mathrm{Cu}^{+}$by following the fluorescence of BCS encapsulated inside LUVs in phosphate buffer $\left(50 \mathrm{mM}, \mathrm{pH}\right.$ 7) upon addition of $\mathrm{CuCl}_{2}$ and sodium ascorbate to create a $\mathrm{Cu}^{+}$gradient. a) Comparison of $\mathrm{Cu}^{+}$receptors 1-3, and control compounds $\mathbf{4}$ and $\mathbf{5}$. b) Transport of $\mathrm{Cu}^{+}$by different concentrations of $\mathbf{2}$.

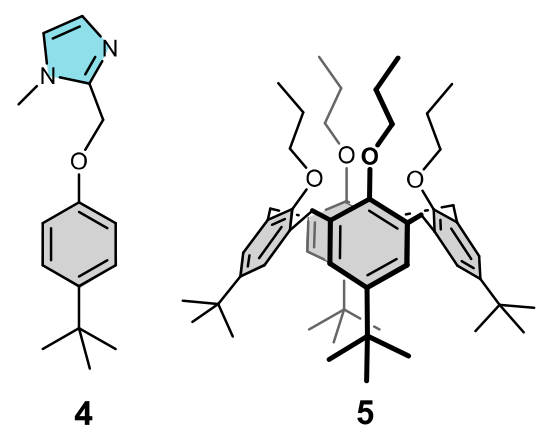

Chart 1. Control compounds 4 and 5.

The $\mathrm{Cu}^{+}$transport process by calixarene 2 was investigated in more detail (see ESI for details). Firstly, the transporter:lipid ratio was varied (Figure $4 \mathrm{~b}$ ) and the initial rates $\left(I_{0}\right)$ when plotted against the transporter concentration showed a linear trend $\left(R^{2}=0.99\right.$, Figure $\left.S 25\right)$. This implies that transporters function independently from each other and transport only one $\mathrm{Cu}^{+}$ion at a time.

Changing the counter anions of the copper salt $\left(\mathrm{SO}_{4}{ }^{2-}\right.$ was used instead $\mathrm{Cl}^{-}$) did not have a significant impact on the rate of $\mathrm{Cu}^{+}$transport (see ESI, Section 4.6), implying that $\mathrm{Cu}^{+}$is not transported by a symport mechanism. Changing the counter cations of the phosphate buffer $\left(\mathrm{K}^{+}\right.$instead of $\left.\mathrm{Na}^{+}\right)$did not give any significant changes either. The ability of calixarene $\mathbf{2}$ to transport $\mathrm{H}^{+}, \mathrm{Na}^{+}$, and $\mathrm{K}^{+}$was further evaluated with $\mathrm{HPTS}$, a $\mathrm{pH}$ sensitive dye (see ESI, Section 4.7). In presence of a $\mathrm{pH}$ gradient, 2 was unable to transport $\mathrm{H}^{+}$, neither by uniport nor by antiport with $\mathrm{Na}^{+}$or $\mathrm{K}^{+}$. Furthermore, $\mathbf{2}$ did not show any $\mathrm{Na}^{+}$or $\mathrm{K}^{+}$ uniport activity in presence of the protonophore carbonyl cyanide $m$-chlorophenyl hydrazine (CCCP). These results indicate that transport of $\mathrm{Cu}^{+}$could not occur by an antiport mechanism with $\mathrm{H}^{+}, \mathrm{Na}^{+}$or $\mathrm{K}^{+}$and that calixarene $\mathbf{2}$ is a highly selective transporter for $\mathrm{Cu}^{+}$.

Having ruled out symport and antiport mechanisms, the $\mathrm{Cu}^{+}$ transport as observed by $\mathbf{2}$ in the BCS assay appears thus to occur by a uniport mechanism. This electrogenic transport process should result in the build-up of a potential gradient, which is however limited by the low $\mathrm{Cu}^{+}$concentration used ( 30 $\mu \mathrm{M})$ and therefore not visible with the membrane potential probe Safranin O.

No transport of $\mathrm{Cu}^{+}$by $\mathbf{2}$ was observed in DPPC liposomes at $25^{\circ} \mathrm{C}$ (gel phase), while transport was retrieved at $45^{\circ} \mathrm{C}$ (fluid phase, Figure S27), in agreement with a mobile carrier mechanism (Figure $3 b$ ). To further demonstrate the ability of 2 to function as a carrier for $\mathrm{Cu}^{+}, \mathrm{U}$-tube experiments were conducted. An aqueous phase was placed at either end of a $\mathrm{CHCl}_{3}$ solution containing $2(1 \mathrm{mM})$. One of the aqueous phases contained $\mathrm{CuCl}_{2}$ and sodium ascorbate $(0.5 \mathrm{mM}$ and $1 \mathrm{mM}$, donor phase), the other was water without any salt (receiving phase). After 7 days, $\mathrm{Cu}^{+}$was detected in the receiving phase as a decrease of the fluorescence of added BCS (Figures S33). The amount of $\mathrm{Cu}^{+}$transported was estimated to be $22 \mu \mathrm{M}$, which represents about $4 \%$ of the $\mathrm{Cu}^{+}$concentration initially present in the donor phase, in agreement with $U$-tube results reported in the literature. ${ }^{22,23}$ These U-tube experiments corroborate 
that $\mathrm{Cu}^{+}$can be transported with imidazole-functionalised calixarenes via a carrier mechanism.

We have demonstrated that a calixarene with two preorganised imidazole groups is capable of selectively extracting $\mathrm{Cu}^{+}$from an aqueous into an organic phase. The bidentate linear coordination of $\mathrm{Cu}^{+}$is at the basis of the observed selectivity for $\mathrm{Cu}^{+}$over other cations, including $\mathrm{Cu}^{2+}$ and $\mathrm{Na}^{+}$. These calixarenes do not only bind $\mathrm{Cu}^{+}$, but are also able to transport $\mathrm{Cu}^{+}$across lipid bilayers, as shown using a newly developed assay with a $\mathrm{Cu}^{+}$sensitive fluorescent dye encapsulated in liposomes. Additional transport studies showed that calixarene $\mathbf{2}$ is highly selective for transport of $\mathrm{Cu}^{+}$ compared to other monovalent cation $\left(\mathrm{Na}^{+}, \mathrm{K}^{+}, \mathrm{H}^{+}\right)$and that transport of $\mathrm{Cu}^{+}$occurs via a uniport mechanism. This is the first time that transmembrane transport of $\mathrm{Cu}^{+}$by synthetic molecules was demonstrated and this study opens a way to further develop $\mathrm{Cu}^{+}$ionophores. These could find applications in the study of $\mathrm{Cu}^{+}$homeostasis and in the development of treatments for channelopathies linked to deficient transmembrane transport of $\mathrm{Cu}^{+}$, such as Menkes and Wilson's diseases. Current treatments for those diseases focus on the symptoms, ${ }^{24}$ while $\mathrm{Cu}^{+}$cationophores could target their cause.

\section{Conflicts of interest}

There are no conflicts to declare.

\section{Acknowledgements}

N.R. thanks the Fonds pour la Formation à la Recherche dans I'Industrie et dans l'Agriculture (FRIA-FRS, Belgium) for his PhD grant. H.V. is Chercheuse Qualifiée of the Fonds de la Recherche Scientifique-FNRS and thanks the European Research Council (ERC starting grant 802727). The authors also thank the ULB, "Fonds Van Buuren" and "Fonds Defay" for grants that enabled the purchase of the fluorescence spectrometer.

\section{Notes and references}

1 R. A. Festa, D. J. Thiele, Curr. Biol. 2011, 21, R877-R883.

2 P. V. van den Berghe, L. W. Klomp, Nutr. Rev. 2009, 67, 658672.

3 H. Kodama, C. Fujisawa, W. Bhadhprasit, Curr. Drug Metab. 2012, 13 (3), 237-250.

4 I. Alfonso, R. Quesada, Chem. Sci. 2013, 4, 3009.

5 This approach is analogous to that of developing anionophores to restore transport of for instance chloride. See also: a) N. Busschaert, P. A. Gale, Angew. Chem. Int. Edit. 2013, 52, 1374-1382; b) H. Valkenier, A. P. Davis, Accounts Chem. Res. 2013, 46, 2898-2909; c) A. Vargas Jentzsch, A. Hennig, J. Mareda, S. Matile, Accounts Chem. Res. 2013, 46, 2791-2800; d) P. A. Gale, J. T. Davis, R. Quesada, Chem. Soc. Rev. 2017, 46, 2497-2519.

6 B. C. Pressman, Annu. Rev. Biochem. 1976, 45, 501-530.

7 C. F. Reusch, E. L. Cussler, AlChE J. 1973, 19, 736-741.

8 D. Magda, P. Lecane, Z. Wang, W. Hu, P. Thiemann, X. Ma, P. K. Dranchak, X. Wang, V. Lynch, W. Wei, et al., Cancer Res. 2008, 68, 5318-5325.

9 S. M. Kaiser, B. I. Escher, Environ. Sci. Technol. 2006, 40, 1784-1791.

10 S. Tardito, I. Bassanetti, C. Bignardi, L. Elviri, M. Tegoni, C. Mucchino, O. Bussolati, R. Franchi-Gazzola, L. Marchiò, J. Am. Chem. Soc. 2011, 133, 6235-6242.

$11 \mathrm{Cu}^{+}$transport through organic phases and through polymeric membranes has been reported: $\mathrm{H}$. Matsumiya, Y. Yatsuya, M. Hiraide, Anal. Bioanal. 2006, 385 (5), 944-947; T. Saito, Sep. Sci. Technol. 1994, 29 (10), 1335-1346.

12 L. L. Clainche, M. Giorgi, O. Reinaud, Eur. J. Inorg. Chem. 2000, 2000, 1931-1933.

13 T. M. DeSilva, G. Veglia, S. J. Opella, Proteins: Struct. Funct Bioinf. 2005, 61, 1038-1049.

14 R. A. Himes, G. Y. Park, A. N. Barry, N. J. Blackburn, K. D. Karlin, J. Am. Chem. Soc. 2007, 129, 5352-5353.

15 M. Sendzik, M. J. Pushie, E. Stefaniak, K. L. Haas, Inorg. Chem. 2017, 56, 15057-15065.

16 A. Maurin, S. Varatharajan, B. Colasson, O. Reinaud, Org. Lett. 2014, 16, 5426-5429.

17 Lowest energy conformation obtained from a conformational search (Monte Carlo Molecular Mechanics) in MacroModel 11.9.011 using the OPLS2005 force field.

18 cLogP values obtained from Chemdraw 15.0.0.

19 A. Ikeda, S. Shinkai, Chem. Rev. 1997, 97 (5), 1713-1734.

20 S. Ogawa, R. Ichiki, M. Abo, E. Yoshimura, Anal. Chem. 2009, $81(21), 9199-9200$.

21 A. Mattiuzzi, I. Jabin, C. Mangeney, C. Roux, O. Reinaud, L. Santos, J.-F. Bergamini, P. Hapiot, C. Lagrost, Nat. Commun. 2012, 3, 1130.

22 G. Grauwels, H. Valkenier, A. P. Davis, I. Jabin, K. Bartik, Angew. Chem. Int. Edit. 2019, 58, 6921-6925.

23 R. A. Harris, B. Farmer, Lipids 1973, 8, 717-721.

24 E. A. Roberts, M. L. Schilsky, Hepatology 2008, 47, 20892111. 